\title{
Nondisease genetic testing: reporting of muscle SNPs shows effects on self-concept and health orientation scales
}

Erynn S Gordon ${ }^{*}, 1$, Heather A Gordish-Dressman ${ }^{1}$, Joseph Devaney ${ }^{1}$, Priscilla Clarkson ${ }^{2}$, Paul Thompson ${ }^{3}$, Paul Gordon ${ }^{4}$, Linda S Pescatello ${ }^{5}$, Monica J Hubal ${ }^{2}$, Emidio E Pistilli ${ }^{4}$, Gary Gianetti ${ }^{5}$, Bethany Kelsey ${ }^{5}$ and Eric P Hoffman ${ }^{1}$

${ }^{1}$ Research Center for Genetic Medicine, Children's National Medical Center, Washington, DC, USA; ${ }^{2}$ Department of Kinesiology, University of Massachusetts Amherst, Amherst, MA, USA; ${ }^{3}$ Division of Cardiology, Hartford Hospital, Hartford, CT, USA; ${ }^{4}$ Department of Human Performance, West Virginia University, Morgantown, WV, USA; ${ }^{5}$ School of Allied Health, University of Connecticut, Storrs, CT, USA

The purpose of this study was to assess the impact of genetic self-knowledge (nondisease genotype information) on individual self-concept and Health Orientation Scale (HOS). Adult volunteers $(n=257)$ were recruited from an ongoing genetic association study identifying muscle quantitative trait loci (QTLs). Participants completed psychosocial assessments before and after 12 weeks of resistance training of the nondominant arm. At study exit, a genetic counselor informed participants of genetic test results on three to four genes that have an association with muscle-related traits, and counseled subjects on the potential significance of these findings. The second psychosocial assessment was performed immediately following this counseling session. The Tennessee Self-Concept Scale v.2 (TSCS:2) and the HOS showed female subjects to have a significantly greater positive change between first and second assessments, relative to male subjects. Most self-concept subscales improved significantly, when 'neutral' genotypes (no anticipated beneficial or deleterious impact) were reported, compared to positive genotypes. TSCS:2 subscales showing improvement included: total $(P=0.013)$; physical $(P=0.004)$; satisfaction $(P=0.019)$; and behavioral $(P=0.047)$. HOS subscales showing improvement included health image concern $(P=0.006) ;$ and health expectations $(P=0.047)$. In conclusion, these results suggest that genetic selfknowledge affects self-concept, consistent with the 'attribution' theory. Individuals who received neutral genetic information attributed positive changes from the exercise program to their own abilities, while those who received positive information were more likely to attribute positive changes to their genetics. This study is limited by the ability to determine the direction of the impact of nondisease genetic information presented to participants.

European Journal of Human Genetics (2005) 13, 1047-1054. doi:10.1038/sj.ejhg.5201449;

published online 8 June 2005

Keywords: self-concept; SNP; health perception

*Correspondence: ES Gordon, Research Center for Genetic Medicine, Children's National Medical Center, 111 Michigan Ave NW, Washington, DC 20010, USA; Tel: 1202884 6065; Fax: 1202884 6014;

E-mail: egordon@cnmcresearch.org

Received 18 October 2004; revised 12 April 2005; accepted 29 April 2005; published online 8 June 2005
Introduction

Genetic testing of individuals is becoming widespread and is no longer reserved for disease-related genes. Indeed, several companies already offer testing for genes related to an individual's 'nutritional' genetic background as well as addictive behavior, reward seeking behavior, athleticism, 
and lifestyle. ${ }^{1-6}$ Such companies claim to provide genetic self-knowledge that will enable the individual to optimize their lifestyle. The validity of such claims are questionable, but the prevalence of these companies attests to the probability that testing for genes not directly related to disease will become increasingly common, if not commonplace. It is not clear how such genetic self-knowledge might affect self-concept and health perception especially when the testing is for genetic traits not related to disease.

Our current understanding of the impact of genetic selfknowledge on self-concept and health perception stems from testing for genetic disease, specifically presymptomatic diagnosis (eg Huntington's disease (HD)), and carrier status for recessive conditions (Cystic fibrosis, Tay Sachs). Psychological changes in self-concept have been observed in response to carrier testing for Tay Sachs in high school students. ${ }^{7}$ Tay Sachs carriers in another study, had a significantly less optimistic view of their own future health $(P<0.01)$ than noncarriers or the random control group. ${ }^{8}$ In a study of carriers for sickle cell trait, there was a belief by noncarriers, that carriers were less healthy, less happy, and less active than carriers perceived themselves to be. ${ }^{9}$ In addition, $43 \%$ of parents of children with sickle cell trait viewed their children as having a disease and $66 \%$ of these parents felt that their children needed dietary supplements in order to remain healthy. ${ }^{10}$ Taken together, these studies suggest that knowledge of one's carrier status for a recessive disease has a negative impact on self-concept.

Predictive testing for late onset disorders such as HD also provides valuable insight into the effect of genetic information in an asymptomatic population. In a 6-year follow-up study of individuals who had undergone predictive testing for $\mathrm{HD}$, most patients (those who tested positive and negative) reported less preoccupation with HD. In addition, those testing positive for HD mutation reported experiencing a relief from anxiety, and noncarriers reported a decrease in psychological distress and higher self-esteem. ${ }^{11}$ These studies suggest that genetic knowledge can have a positive effect on health perception.

To our knowledge, there are no studies of the impact of genetic self-knowledge for nondisease traits on self-concept or health perception. Testing for genetic traits that are considered 'normal variants' are controversial with fears of eugenics making such studies difficult to initiate despite the current demand for these tests.

Genetic predisposition to muscle strength, size, and performance are commonly accepted by the general population as both genetically determined ${ }^{12-17}$ and subject to environmental influences (eg training). Thus, we believed that testing for a series of single-nucleotide polymorphisms (SNPs) associated with predispositions to specific muscle traits (ACE, CNTF, gamma sarcoglycan (GS), UCP2) would not raise the specter of eugenics, while also revealing influences of genetic knowledge on self-concept and Health Orientation Scales (HOSs).
Here, we report the study of 235 normal volunteer subjects from three universities, enrolled in a supervised resistance-training program designed to identify major muscle quantitative trait loci (QTLs) for muscle strength and size. Genotypes were reported back to subjects, and changes in self-concept were studied as a function of the nature of the genetic self-knowledge (neutral, or positive).

\section{Methods \\ Subjects}

Participants in the present study include 259 healthy volunteers, ages 18-40 years, recruited over 2.5 years from three of eight sites participating in a 4-year, NIH funded, functional SNPs associated with muscle size, and strength study (FAMuSS). The three sites (WVU, Amherst, UConn) were chosen based on their semester scheduling and their proximity to the genetics coordinating site (CNMC) to allow one genetic counselor to complete all interview and disclosure sessions. All subjects enrolled at the above sites were offered participation in the genetics and self-concept study. The details of the FAMuSS study have been published elsewhere. ${ }^{18}$ In brief, healthy men and women, who, by self-report did not participate in resistancetraining activities for at least 1 year prior to enrollment, were recruited through fliers and advertisements. Each participant underwent measurement of their elbow flexor and extensor muscles' size and strength before and after 12 weeks of exercise training of their nondominant arm. The goal of the FAMuSS study is to establish genetic associations between SNPs and muscle size and/or strength; therefore, participants provided a blood sample for genetic testing. Genetic results were only available to participants in the self-concept study. The Institutional Review Board at each site approved both this project and the FAMuSS study.

\section{Study design}

After giving written, informed consent, participants completed self-concept assessments (Tennessee Self-Concept Scale (TSCS), HOS, demographic information, test of genetic knowledge and open-ended questions) at study entry (time 1). Participants then completed 12 weeks of exercising training followed by genetic counseling and disclosure of genotype information. All self-concept assessments were then repeated (time 2). The same genetic counselor conducted all results disclosure sessions.

The first 48 subjects completed all assessments on paper, which were later entered into the study database. All assessment tools were then transferred to secure web databases, enabling remote data entry by the subject for subsequent subjects. Copyright permission was obtained for all web-administered questionnaires. In order to provide consistency between institutions, preserve the integrity of the data and the privacy of the participant, all participants were required to complete the web-based 
self-concept assessment within the department of exercise science at each respective school using a unique subject ID. Polymorphisms were selected based on previously established published associations (Table 1). Genotyping methods have been described. ${ }^{24}$

\section{Genetic counseling session}

Before receiving personalized information, participants were provided with basic information on genetics to help them understand their results. Topics covered included the definition of genes, how many genes humans have and how many may be involved in muscle function and structure, the definition of a polymorphism, definition of an allele, a reminder that this study was not looking for disease-related changes, the concept of an association versus a cause and effect relationship and how the genes were chosen. Each participant was then given individual results for ACE, CNTF, and UCP2 genes. A subset of subjects (40/257) was also given their genotype for GS. The introduction and discussion of each genotype was scripted for consistency. For each gene, participants were told whether they were homozygous for the polymorphism, and heterozygous or homozygous for the wild-type and a scripted interpretation of the data were provided. Examples of genotype/phenotype result reporting are as follows:

All neutral genotypes (homozygous wild-types and heterozygotes): 'You have been found to have two copies of the common allele/one copy of the common allele and one copy of the allele with the polymorphism, there are no changes in athletic performance, strength or muscle mass associated with this finding'.

Positive genotypes: 'You have been found to have two copies of the V allele in the UCP-2 gene. Individuals with two copies of the $\mathrm{V}$ allele appear to expend less energy doing the same activities as other individuals and therefore may feel as though they have more energy and need to use less effort in exercising'.
After receiving genetic results, participants completed the second self-concept assessment and met with the genetic counselor to discuss any questions or concerns.

\section{Self-concept and HOSs:}

Tennessee self-concept scale - $2^{25}$ The TSCS uses 82 questions rated on a five-point Likert scale to assess total self-concept as well as eight subscales including satisfaction, behavior, physical, moral, personal, family, social, and academic self-concept. The tool contains inconsistency and 'faking good' subscales to provide a statistical basis for evaluating the honesty and consistency of the participant.

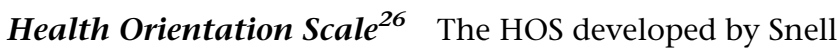
is particularly applicable to the study as it assesses psychological variables related to physical health. The 10 validated subscales in this self-assessment tool include personal health consciousness, health image concern, health anxiety, health esteem, and confidence, motivation to avoid unhealthiness, motivation for healthiness, health internal control, health external control, health expectations, and health status. ${ }^{26}$

\section{Coding of neutral and nonneutral combined genotypes}

To assess the impact of this genetic knowledge, subjects were placed into one of three genotype effect groups: positive, defined as having received at least one genotype associated with a positive ability to gain muscle size and/or strength and no genotypes with negative implications; negative, defined as having received at least one genotype associated with a negative ability to gain strength (homozygosity for the CNTF polymorphism associated with lower baseline strength) and no genotypes with positive implications; and neutral, defined as having only received genotype results, which have no impact on an individuals' ability to gain muscle size and/or strength.

Table 1 Published associations for reported polymorphisms

\begin{tabular}{|c|c|c|}
\hline Gene & Polymorphism & Association \\
\hline$A C E$ & $\begin{array}{l}\text { Insertion/deletion ( } 287 \text { base pair Alu repeat } \\
\text { sequence within intron } 16)\end{array}$ & $\begin{array}{l}\text { Endurance activities (rowing, high altitude mountaineering), } \\
\text { resistance training and overall physical activity } 19,20\end{array}$ \\
\hline CNTF & $G \rightarrow A$ substitution within splice site in intron 1 & $\begin{array}{l}\text { AA genotype has been associated with lower baseline strength } \\
\text { than participants with either the GG or GA genotype }\end{array}$ \\
\hline UCP-2 & A55V & $\begin{array}{l}\mathrm{V} / \mathrm{V} \text { genotype associated with higher exercise efficiency at } 40 \% \\
\mathrm{VO}_{2 \max } \text { than } \mathrm{V} / \mathrm{A} \text { or } \mathrm{A} / \mathrm{A} \text {. Higher spontaneous physical activity } \\
\text { also associated with the } \mathrm{V} / \mathrm{V} \text { genotype }\end{array}$ \\
\hline $\begin{array}{l}\text { Gamma } \\
\text { sarcoglycan }\end{array}$ & S287N & $\begin{array}{l}\text { Studies of body builders and football players suggest } \\
\text { polymorphism associated with increased muscle size and } \\
\text { strength (unpublished) }^{a}\end{array}$ \\
\hline
\end{tabular}

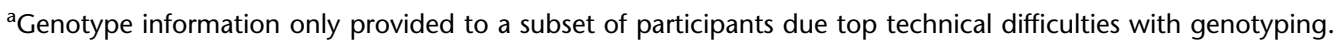


This stratification permitted a comparison of how positive versus neutral nondisease genetic information affected selfconcept. Owing to the low allele frequency of the CNTF polymorphism only 17 individuals received negative information; therefore, all analyses were limited to comparisons of individuals receiving only neutral and positive information.

Assessment of longitudinal change in TSCS:2 and HOS Changes in self-concept between times 1 and 2 were determined by calculating the effect size for each scale measured by the TSCS:2. T-scores ascertained by the TSCS: 2 are designed to have a mean of 50 and a SD of 10 . This design allowed us to calculate effect sizes for each measure and to compare effect sizes between two or more subscales. Effect sizes of $0.20,0.50$, and 0.80 are defined as small, medium, and large effects, respectively. Changes in health orientation measures were determined by finding the differences in each HOS subscale between times 1 and 2 .

\section{Statistical analyses}

Statistical analyses were performed using Stata, Version 7.0 (Stata Corp, College Station, TX, USA). Independent $T$-tests compared mean effect sizes and mean health orientation changes between genders and age groups (18-25 versus $\geqslant 26$ years), while one-way analysis of variance compared means between participating sites. In order to measure the combined effect of genotype and demographic characteristics, multivariate analyses using generalized linear models were used in place of ANCOVAs due to unbalanced data. The normality of all continuous variables was verified using the Anderson-Darling normality test.

\section{Excluded subjects}

Based on their TSCS: 2 results, twenty-two subjects were excluded prior to statistical analysis. In all, 14 subjects who had an inconsistency $T$-score $\geqslant 70$ and seven subjects who had a faking good $T$-score of $>70$ and a self-criticism $T$ score $\leqslant 40$ were excluded, according to TSCS: 2 guidelines. ${ }^{25}$ One subject was excluded due to a language barrier and an inability to understand the questions.

\section{Results}

Study population

The 218 analyzed subjects included 120 (55.1\%) female subjects and 98 (44.9\%) male subjects, with a majority $(81.7 \%)$ being Caucasian (Table 2). The subjects had a mean age of $24.9 \pm 6.0$ years, ranging from the youngest at 18 years to the oldest at 41 years. Muscle size and strength changes during the unilateral training sessions have been reported elsewhere. ${ }^{27}$

\section{Comparison of self-concept effect size among demographic characteristics}

Changes in mean self-concept effect sizes and health orientation were compared between genders and age groups using Student's T-tests (Table 3). Comparisons between genders revealed several significant gender differences in TSCS:2 measurements. Female subjects had significantly greater mean behavior effect size (F: $0.181 \pm 0.622$ versus $\mathrm{M}:-0.019 \pm 0.882 ; P=0.050)$, mean personal effect size (F: $0.196 \pm 0.542$ versus $M$ : $-0.019 \pm 0.904 ; P=0.030$ ), and mean academic effect size (F: $0.116 \pm 0.487$ versus $\mathrm{M}:-0.093 \pm 0.850 ; \quad P=0.024$ ) compared to male subjects. There were no significant

Table 2 Demographic characteristics of analyzed subject population

\begin{tabular}{|c|c|c|c|}
\hline Characteristic & $\begin{array}{c}\text { All subjects } \\
N(\%)\end{array}$ & $\begin{array}{c}\text { Genotype e } \\
\text { Neutral group } \\
N(\%)\end{array}$ & $\begin{array}{c}\text { ffect groups } \\
\text { Positive group } \\
N(\%)\end{array}$ \\
\hline \multicolumn{4}{|l|}{ Age group } \\
\hline $18-20$ years & $63(28.9 \%)$ & 19 (31.7\%) & $44(27.8 \%)$ \\
\hline $21-25$ years & $80(36.7 \%)$ & $16(26.7 \%)$ & $64(40.5 \%)$ \\
\hline $26-30$ years & 35 (16.0\%) & 12 (20.0\%) & $23(14.6 \%)$ \\
\hline $31+$ years & $40(18.3 \%)$ & $13(21.6 \%)$ & $27(17.1 \%)$ \\
\hline \multicolumn{4}{|l|}{ Gender } \\
\hline Female & $120(55.1 \%)$ & 30 (51.7\%) & $90(56.3 \%)$ \\
\hline Male & $98(44.9 \%)$ & $38(48.3 \%)$ & $70(43.7 \%)$ \\
\hline \multicolumn{4}{|l|}{ Ethnicity } \\
\hline African-American & $2(0.9 \%)$ & $0(0.0 \%)$ & $2(1.2 \%)$ \\
\hline Asian & $22(10.1 \%)$ & $7(12.1 \%)$ & $15(9.4 \%)$ \\
\hline Caucasian & $178(81.7 \%)$ & $48(82.8 \%)$ & $130(81.3 \%)$ \\
\hline Hispanic & $9(4.1 \%)$ & $2(3.4 \%)$ & $7(4.4 \%)$ \\
\hline Other & $7(3.2 \%)$ & $1(1.7 \%)$ & $6(3.7 \%)$ \\
\hline
\end{tabular}

Table 3 Significant gender differences in TSCS:2 and HOS measures

\begin{tabular}{|c|c|c|c|c|c|}
\hline \multirow[b]{2}{*}{ Selfconcept measure } & \multirow[b]{2}{*}{ P-value } & \multicolumn{2}{|c|}{ Females } & \multicolumn{2}{|c|}{ Males } \\
\hline & & $N$ & Mean $\pm S D$ & $N$ & Mean $\pm S D$ \\
\hline Physical selfconcept & 0.028 & 130 & $0.137 \pm 0.524$ & 105 & $-0.045 \pm 0.746$ \\
\hline Personal selfconcept & 0.009 & 130 & $0.212 \pm 0.543$ & 105 & $-0.035 \pm 0.883$ \\
\hline Academic selfconcept & 0.019 & 130 & $0.120 \pm 0.479$ & 105 & $-0.083 \pm 0.829$ \\
\hline Total selfconcept & 0.028 & 130 & $0.182 \pm 0.495$ & 105 & $-0.015 \pm 0.864$ \\
\hline
\end{tabular}


differences in mean health orientation changes between male subjects and female subjects. There were also no significant differences in mean self-concept effect sizes or mean health orientation changes between the 18-25 and $\geqslant 26$ years age groups.

As a result of the observed significant gender effects, all multivariate analyses were adjusted for gender. While feedback regarding strength or size changes was not recorded for each participant, different practices were used by each site (some provided feedback, others did not); therefore, analyses were also adjusted for study site to avoid any possible confounding effect of location.

\section{Multivariate comparison of self-concept effect size among genotype effect groups}

Subjects who received only neutral genotypes had greater mean physical self-concept effect size $(P=0.004)$, satisfaction self-concept effect size $(P=0.019)$, behavioral selfconcept effect size $(P=0.017)$ and total self-concept effect size $(P=0.013)$ than subjects who received at least one positive genotype (Table 4 ). They also had a lower mean health image concern change $(P=0.006)$ and a greater change in health expectations $(P=0.047)$ than subjects who received at least one positive genotype (Table 5).

Owing to the small size of the group receiving negative information and because all but one also received positive

Table 4 Comparison of TSCS:2 measures between neutral and positive genotype groups

\begin{tabular}{|c|c|c|c|c|c|c|c|}
\hline \multirow[b]{2}{*}{ Measure } & \multicolumn{2}{|c|}{ Time 1} & \multicolumn{2}{|c|}{ Time 2} & \multicolumn{3}{|c|}{ Difference } \\
\hline & $\begin{array}{l}\text { Neutral group } \\
\text { mean } \pm S D \\
(N=58)\end{array}$ & $\begin{array}{c}\text { Positive group } \\
\text { mean }+S D \\
(N=160)\end{array}$ & $\begin{array}{c}\text { Neutral group } \\
\text { mean } \pm S D \\
(N=58)\end{array}$ & $\begin{array}{c}\text { Positive group } \\
\text { mean } \pm S D \\
(N=160)\end{array}$ & $\begin{array}{c}\text { Neutral group } \\
\text { mean } \pm S D \\
(N=58)\end{array}$ & $\begin{array}{c}\text { Positive group } \\
\text { mean } \pm S D \\
(N=160)\end{array}$ & $P$-value $e^{* *}$ \\
\hline Satisfaction & $46.13 \pm 9.24$ & $48.71 \pm 9.05$ & $48.93 \pm 11.25$ & $48.57 \pm 9.37$ & $0.287 \pm 0.115$ & $-0.015 \pm 0.069$ & 0.019 \\
\hline Behavior & $.80^{\mathrm{a}}$ & $46.53 \pm 8.72$ & $71 \pm 11.20^{a}$ & $46.83 \pm 9.58$ & $0.275 \pm 0.099$ & $0.029 \pm 0.060$ & 0.017 \\
\hline Physi & $21 \pm 8.09^{\mathrm{a}}$ & $50.26 \pm 6.74$ & $.83 \pm 9.67^{a}$ & 3 & $0.239 \pm 0$. & $-0.008 \pm 0.051$ & 0.004 \\
\hline Mora & $30+8.54$ & $47.05+8.15$ & $45.30+9.15$ & $46.19+9.19$ & $0.001+0.108$ & $-0.077+0.065$ & NS \\
\hline Personal & $45.75 \pm 8.90^{\mathrm{a}}$ & $48.61 \pm 8.17^{\mathrm{b}}$ & $48.39 \pm 10.92^{\mathrm{a}}$ & $49.09 \pm 9.37$ & $0.256 \pm 0.96$ & $0.049 \pm 0.058$ & NS \\
\hline Family & $46.54 \pm 8.52$ & $47.56 \pm 9.15$ & $48.59 \pm 10.97$ & $47.73 \pm 9.60$ & $0.206 \pm 0.098$ & $0.015 \pm 0.059$ & NS \\
\hline Society & $46.83 \pm 8.98$ & $48.73 \pm 8.01$ & $48.69 \pm 12.12$ & $48.65 \pm 10.41$ & $0.172 \pm 0.102$ & $0.018 \pm 0.062$ & NS \\
\hline Academic & $48.85 \pm 7.47$ & $50.30 \pm 7.45$ & $50.08 \pm 9.89$ & $50.26 \pm 8.87$ & $0.117 \pm 0.089$ & $-0.006 \pm 0.054$ & NS \\
\hline & \pm 10.11 & $48.22 \pm 8.41$ & $48.22 \pm 11.08^{a}$ & $48.38 \pm 9.50$ & $0.269 \pm 0.092$ & $0.019 \pm 0.056$ & 0.013 \\
\hline
\end{tabular}

${ }^{* *} P$-value of genotype effect from ANCOVA comparing mean difference between neutral and positive groups adjusted for gender and study site. ${ }^{a}$ Neutral group:time 1 mean significantly different from time 2 mean (behavior $P=0.027$; physical $P=0.027$; personal $P=0.045$; total $P=0.044$ ).

${ }^{\mathrm{b}}$ Significantly different means between neutral and positive groups at time $1(P=0.026)$.

Table 5 Comparison of HOS measures between neutral and positive genotype groups

\begin{tabular}{|c|c|c|c|c|c|c|c|}
\hline \multirow[b]{2}{*}{ Measure } & \multicolumn{2}{|c|}{ Time 1} & \multicolumn{2}{|c|}{ Time 2} & \multicolumn{3}{|c|}{ Difference } \\
\hline & $\begin{array}{l}\text { Neutral group } \\
\text { mean } \pm S D \\
(N=58)\end{array}$ & $\begin{array}{c}\text { Positive group } \\
\text { mean }+S D \\
(N=160)\end{array}$ & $\begin{array}{l}\text { Neutral group } \\
\text { mean }+S D \\
(N=58)\end{array}$ & $\begin{array}{l}\text { Positive group } \\
\text { mean }+S D \\
(N=160)\end{array}$ & $\begin{array}{l}\text { Neutral group } \\
\text { mean } \pm S D \\
(N=58)\end{array}$ & $\begin{array}{l}\text { Positive group } \\
\text { mean }+S D \\
(N=160)\end{array}$ & $P$-value ** \\
\hline Total & $156.14 \pm 17.13$ & $158.13 \pm 18.57$ & $156.81 \pm 18.45$ & $158.35 \pm 18.62$ & $0.240 \pm 1.60$ & $0.121 \pm 0.953$ & NS \\
\hline $\begin{array}{l}\text { Personal health } \\
\text { consciousness }\end{array}$ & $1878+340$ & $1920+355$ & $1946 \overline{+} 332$ & $1931 \overline{+} 353$ & $1.003 \pm 0.448$ & $0.018 \pm 0.266$ & NS \\
\hline Health image concern & $12.66 \pm 4.24^{\mathrm{a}}$ & $11.74 \pm 5.21$ & $11.33 \pm 4.50^{\mathrm{a}}$ & $11.83 \pm 5.05$ & $-1.548 \pm 0.522$ & $0.155 \pm 0.309$ & 0.006 \\
\hline Health anxiety & $12.64 \pm 4.04^{\mathrm{a}}$ & $11.79 \pm 4.39^{\mathrm{b}}$ & $9.67 \pm 4.88^{\mathrm{a}}$ & $10.21 \pm 9.37^{b}$ & $-2.919 \pm 0.665$ & $-1.157 \pm 0.393$ & NS \\
\hline $\begin{array}{l}\text { Health-esteem and } \\
\text { confidence }\end{array}$ & $15.64 \pm 3.01$ & $16.50 \pm 2.97$ & $16.12 \pm 3.05$ & $16.59 \pm 2.57$ & $0.567 \pm 0.389$ & $-0.155 \pm 0.230$ & NS \\
\hline $\begin{array}{l}\text { Motivation to avoid } \\
\text { unhealthiness }\end{array}$ & $17.69 \pm 3.54$ & $17.79 \pm 3.97$ & $17.96 \pm 3.34$ & $18.11 \pm 3.81$ & $0.193 \pm 0.424$ & $0.143 \pm 0.251$ & NS \\
\hline $\begin{array}{l}\text { Motivation for } \\
\text { healthiness }\end{array}$ & $16.79 \pm 3.91$ & $16.77 \pm 4.37$ & $17.19 \pm 4.11$ & $17.17 \pm 4.17$ & $0.217 \pm 0.380$ & $0.269 \pm 0.226$ & NS \\
\hline Health internal control & $20.86 \pm 3.23$ & $21.53 \pm 3.08$ & $20.75 \pm 3.36$ & $21.28 \pm 3.29$ & $-0.174 \pm 0.491$ & $-0.240 \pm 0.291$ & NS \\
\hline Health external control & $10.21 \pm 3.68$ & $9.33 \pm 3.65$ & $10.37 \pm 3.84$ & $9.58 \pm 3.62$ & $0.183 \pm 0.517$ & $0.256 \pm 0.306$ & NS \\
\hline Health expectations & $17.02 \pm 3.68^{\mathrm{a}}$ & $17.89 \pm 3.75$ & $17.88 \pm 3.57^{\mathrm{a}}$ & $17.97 \pm 2.62$ & $1.111 \pm 0.429$ & $-0.033 \pm 0.254$ & 0.047 \\
\hline Health status & $14.79 \pm 3.66^{\mathrm{a}}$ & $15.97 \pm 4.07^{b}$ & $15.74 \pm 3.57^{a}$ & $16.44 \pm 3.79^{b}$ & $1.034 \pm 0.438$ & $0.520 \pm 0.259$ & NS \\
\hline
\end{tabular}

${ }^{* *} P$-value of genotype effect from ANCOVA comparing mean difference between neutral and positive groups adjusted for gender and study site. ${ }^{a}$ Neutral group:time 1 mean significantly different from time 2 mean (Health image concern $P=0.007$; Health anxeity $P<0.001$; Health expectations $P=0.038$; Total $P=0.004$ ).

bositive group:time 1 mean significantly different from time 2 mean (Health anxiety $P<0.001$; Health Status $P=0.044$ ). 
information $(n=17)$, no analysis was performed on this group.

\section{Discussion}

The goal of this current study was to determine the effect of reporting of nondisease genetic information on muscle performance in a cohort of university students enrolled in a genetics and exercise program. Testing for disease traits can alter an individual's self-concept; however, we know of no previous reports studying the psychosocial effects of nondisease testing. This study is an initial step to determine whether genetic testing in normal individuals for nondisease traits is a beneficial form of 'selfknowledge'.

In this study, we saw a consistent change in both selfconcept and HOSs. Subjects who received neutral genotype data showed statistically significant improvements in four of nine TSCS: 2 self-concept scores, (total, physical, behavior, and satisfaction). Those individuals who received 'positive' genotype information showed no change in selfconcept scales. Within-group analyses showed statistically significant changes in behavioral, physical, personal, and total self- concept when TSCS: 2 scores were compared between times 1 and 2 within the 'neutral' genotype group. No changes were seen in the positive group in withingroup analyses (Table 4). The only subscale that did not show at least a trend towards improvement was moral selfconcept. This subscale measures a person's perception of moral worth. As this study was not related to moral behavior or choice, this subscale might be expected to show the least effect, as we observed. Indeed, this subscale could be viewed as an internal negative control for this study.

In HOS subscales, statistically significant differences were seen in both the 'neutral' and 'positive' genotype groups when within-group and between-group comparisons were done. Within the 'neutral' genotype group (between times 1 and 2) significant changes were seen in health image concern, health anxiety, health expectations, and health status. Within the 'positive' genotype group, differences were seen in health anxiety and health status. Analyses between groups revealed differences in health image concern and health expectations, whereby health expectations showed statistically significant improvements in the neutral group, while health image concern showed a significant decrease (Table 5).

There are two possible interpretations of this data. First, 'attribution theory' could be applied to our observations. The three dimensions of attribution theory attest that humans seek to explain events, behaviors, and observations and attribute the cause of those events in a logical manner. First is Locus of Control, which suggests that things are either internally or externally driven. The second dimension, Stability, addresses the ability of an assigned cause to change over time. The third is Controllability, which describes the extent to which one can control the assigned cause. ${ }^{28,29}$ We suggest that the changes in self-concept that we observed in the neutral group are the result of the third dimension of the attribution theory. Individuals may view experiences or events as either controllable (influenced by action or will power) or uncontrollable (eg genetics). ${ }^{30}$ Genetic predisposition is consistent with an internal locus of control (rather than external cause), yet it is viewed as an uncontrollable factor. Participants who received neutral genotype information had improved physical self-concepts because they viewed observed physical changes as being under their control. We hypothesize that these individuals attributed any perceived positive changes in their bodies to controllable factors such as drive, motivation, and commitment to exercise, rather than attributing it to uncontrollable internal factors such as genetics.

Participants who were told that their genetic make-up had an influence on their physical state (positive genotype group) assigned any perceived physical changes to uncontrollable, albeit internal forces (their genetic makeup) rather than controllable factors such as hard work or personal motivation. This attribution to uncontrollable factors resulted in no change in self-concept scores within this positive group (time 1 versus time 2) or between groups (positive versus neutral).

We saw similar results in behavioral self-concept (how individuals view or perceive their own behavior and the control they may have over their behavior ${ }^{25}$ ), and satisfaction (which reflects self-acceptance and level of satisfaction with oneself ${ }^{25}$ ). The increase in mean behavior and satisfaction observed in the group receiving neutral information again supports the theory that participant control, as opposed to genetic predisposition, results in personal satisfaction.

Total self-concept effect sizes followed the same pattern as physical, behavioral, and satisfaction measures. Total self-concept is considered the most important score on the TSCS:2, reflecting an individual's overall self-concept and self-esteem. $^{25}$ The lack of ownership of any perceived physical gains or successes negated any self-concept benefit from exercise alone and therefore resulted in no change in self-concept measures in the positive group.

In their responses on the HOS, individuals who received neutral genetic information adopted a more optimistic view of their future health and their ability to achieve a healthy lifestyle. The optimism reflected by recipients of neutral information on this measure may reflect a sense of control over future health and fitness.

The second theory that we must consider in the light of our results is that all subjects would have shown an improvement of the same TSCS: 2 and HOS scales independent of genotype information due to the exercise program. 
One could hypothesize that subjects receiving positive information showed a blunting of the otherwise expected increase in self-concept and HOS scales. In other words, positive genotype data had a negative impact on selfconcept and HOS scales.

There has been significant investigation into the effect of exercise on self-concept. Multiple studies have indicated that adults and children who enrolled in a regular exercise regime experience improved self-concept compared to nonexercising controls. ${ }^{31-34}$ Weight training has been found to have greater impact on self-concept than aerobic activity or inactivity, ${ }^{34}$ and results have been shown to persist at least 12 months after exercise. ${ }^{35}$ What must be considered here is whether the attribution of perceived physical changes to one's effort and personal success after receipt of neutral genetic information is powerful enough to cause an increase in selfconcept above that which could be expected from exercise alone, therefore supporting the attribution theory, or whether positive genetic information alone is perceived in such a negative light that it is able to blunt the positive effect of exercise. We must also consider and extricate the impact of any true physical changes on self-concept from perceived change. Preliminary analyses show that there was no change between the neutral and positive groups with respect to absolute difference in 1 RM measures, percent change in $1 \mathrm{RM}$ or percent change in isometric strength. A statistically significant difference in absolute isometric strength $(P=0.05)$ was observed between groups with individuals who received positive genotype information having a larger change in isometric strength $(20.30 \pm 1.54)$ than the neutral genotype group $(13.17 \pm 3.62)$. This preliminary data showing that individuals in the positive genotype group actually gained more strength further demonstrates the impact of perceived control and the positive impact that it can exert on self-concept.

A limitation of the present study is the lack of an independent control arm to measure the cause of the change. While the addition of a control arm (exercise only, no genetic information) was considered, this would have required the involvement of a fourth site. Concerns over variation between sites and exercise trainers guided our decision not to pursue this study design. Future studies should include both an exercise-only arm as well as a genetic-information-only arm in order to truly tease out the contribution of each of these influential factors. In addition, as reflected in Table 2, the study population was predominantly Caucasian. Future studies should strive to include a more racially and ethnically diverse population.

As the understanding of the genetic underpinnings for variations in muscle performance increases, there is significant potential for both use and misuse. ${ }^{36}$ Positive uses of nondisease genetic information and the impact of self-concept stem from our knowledge of the impact of self-concept on behavior. Studies in diabetes and cardiovascular disease show that higher self-concept results in risk-reduction behaviors, ${ }^{37,38}$ increased regular exercise, and better self-care practices. ${ }^{31,39,40}$ The evidence for the impact of self-concept in the modification of behavior in both a disease state as well as daily self-care illustrates the importance of examining the self-concept variable as a predictor of potential behavior modification in both the disease and nondisease arenas, including the importance of assessing this variable in the realm of genetic testing for disease and nondisease factors. Our data suggest that genetic self-knowledge has the potential to have relatively wide-ranging effects on future physical activity and health behavior.

Of greater concern and public debate is the potential misuse of nondisease genetic information. Examples of potential misuse range from athletic doping to 'designer babies'. Recent studies have highlighted the increasing prevalence of both designer steroids and EPO in competitive athletes. ${ }^{41,42}$ Although the concept of designer babies has been discussed for years, the possibility of this coming to fruition is closer now then ever before. There has been significant discussion in many countries and by the World Health Organization regarding the limitation of prenatal testing and assisted reproductive options such as preimplantation genetic diagnosis (PGD) to severe diseases that will have a large and immediate impact on the health of the child. ${ }^{43,44}$ Still, genetic selection for 'benign' traits has been deemed acceptable under certain conditions including benefit to the child, equal access to services, and the absence of clear disadvantage. ${ }^{45}$ There are several ethical dilemmas inherent to limiting genetic testing for reproductive purposes (prenatal testing for PDG), and the line between disease and trait can be blurred. For example, there are forms of short stature that are considered pathologic and others that are considered merely familial traits, but the extent to which they impact the individual may be quite similar. If these lines continue to blur further, it will remain unclear whether the availability of reproductive options can be made available in a way that promotes both fairness and informed consent. $^{46,47}$

As research on nondisease genes moves forward, further study is warranted on the long-term psychological impact of nondisease genetic information as well as careful consideration of the ethical implications of the use of nondisease genetic information.

\section{Acknowledgements}

We thank Dr Thomas $W$ Miller at the University of Connecticut for his assistance and support. This work was supported in part by a grant from the NIH (NS40606) with cosupport from NINDS, NIA, and NIAMS. The assistance of the Parsons Family Foundation is gratefully acknowledged. 


\section{References}

1 www.genovations.com.

2 www.sciona.com.

3 www.docbluminc.com/imagene.htm.

4 www.signaturegenetics.com.

5 www.nugenix.com.

6 www.genetictechnologies.com/au.

7 Clow CL, Scriver CR: Knowledge about and attitudes toward genetic screening among high school students: the Tay Sachs experience. Pediatrics 1977; 59: 86-91.

8 Marteau TM, van Duijn M, Ellis I: Effects of genetic screening on perceptions of health: a pilot study. J Med Genet 1992; 29: 24-26.

9 Woolridge EQ, Murray R: The health orientation scale: a measure of feeling about sickle cell trait. Soc Biol 1988; 35: 123-136.

10 Hampton ML, Anderson J, Lavizzo BS, Bergman AB: Sickle cell 'nondisease': a potentially serious public health problem. Am J Dis Child 1974; 128: 58-61.

11 Taylor CA, Myers R: Long-term impact of Huntington Disease linkage testing. Am J Med Genet 1997; 70: 365-370.

12 Reed T, Fabsitz RR, Selby JV, Carmelli D: Genetic influences and grip strength norms in the NHLBI twin study males aged 59-69. Ann Hum Biol 1991; 18: 425-432.

13 Arden NK, Spector TD: Genetic influences on muscle strength, lean body mass, and bone mineral density study. J Bone Miner Res 1997; 12: 2076-2081.

14 Frederiksen H, Gaist D, Petersen HC et al: Hand grip strength: a phenotype suitable for idnetifying genetic variants affecting midand late- life physical functioning. Genet Epidemiol 2002; 23: $110-122$.

15 Thomis MA, Beunen GP, Maes $\mathrm{HH}$ et al: Strength training: importance of genetic factors. Med Sci Sports Exerc 1998a; 30: 724-731.

16 Thomis MA, Beunen GP, Van Leemputte M et al: Inheritance of static and dynamic arm strength and some of its determinants. Acta Physiol Scand 1998b; 163: 59-71.

17 Tiainen K, Sipila S, Alen M et al: Heritability of maximal isometric muscle strength in older female twins. J Appl Physiol 2004; 96: 173-180.

18 Thompson PD, Moyna N, Seip R et al: Functional polymorphisms associated with human muscle size and strength. Med Sci Sports Exerc 2004; 36 (7): 1132-1139.

19 Montgomery $\mathrm{H}$, Clarkson P, Barnard M et al: Angiotensinconverting-enzyme gene insertion/deletion polymorphism and response to physical training. Lancet 1999; 353: 541-545.

20 Gayagay G, Yu B, Hambly B et al: Elite endurance athletes and the ACE I allele-the role of genes in athletic performance. Hum Genet 1998; 103: 48-50.

21 Roth SM, Schrager MA, Ferrell RE et al: CNTF genotype is associated with muscular strength and quality in humans across the adult age span. I Appl Physiol 2001; 90: 1205-1210.

22 Buemann B, Schierning B, Toubro S et al: The association between the val/ala-55 polymorphism of the uncoupling protein 2 gene and exercise efficiency. Int J Obes Relat Metab Disord 2001; 25: 4467-4471.

23 Astrup A, Toubro S, Dalgaard LT et al: Impact of the v/v 55 polymorphism of the uncoupling protein 2 gene on 24-h energy expenditure and substrate oxidation. Int J Obes Relat Metab Disord 1999; 23: $1030-1040$.

24 Clarkson PM, Devaney JM, Gordish-Dressman H et al: ACTN3 Genotype is Associated with Increases in Muscle Strength and
Response to Resistance Training in Women. J Appl Physiol 2005, February 17 [E-pub ahead of print].

25 Fitts WH, Warren WL: Tennessee self-Concept Scale: Second Edition (TSCS:2). Los Angeles: Western Psychological Services, 1996.

26 Snell WE, Johnson G, Lloyd PJ, Hoover MW: The Health Orientation Scale: A measure of psychological tendencies associated with health. Eur J Personal 1991; 5: 169-183.

27 Hubal MJ, Gordish-Dressman H, Thompson PD et al: Variability in muscle size and strength gain following unilateral resistance training. Med Sci Sports Exerc, in press.

28 Weiner B: A theory of motivation for some classroom experinces. J Educ Pyschol 1979; 71: 3-25.

29 Weiner B: An attributional theory of achievement motivation and emotion. Psychol Rev 1985; 92: 548-573.

30 Weiner B: Judgments of Responsibility: A Foundation for a Theory of Social Conduct. New York: Guilford, 1995.

31 Overbay JD, Purath J: Self-concept and health status is elementary-school-aged children. Issues Compr Pediatr Nurs 1997; 20: 89-101.

32 Stein PN, Motta RW: Effects of aerobic and non-aerobic exercise on depression and self-concept. Percept Mot Skills 1992; 74: $79-89$.

33 Ossip-Klein DJ, Boyne E, Bowman ED et al: Effects of running or weight lifting on self-concept in clinically depressed women. J Consult Clin Psychol 1989; 57: 158-161.

34 Tucker LA: Effect of a weight-training program on the selfconcepts of college males. Percept Mot Skills 1982; 54: 1055-1061.

35 DiLorenzo TM, Bargman EP, Stucky-Ropp R et al: Long-term effects of aerobic exercise on psychological outcomes. Prev Med 1999; 28: $75-85$.

36 Rankinen T, Perusse L, Rauramaa R et al: The human gene map for performance and health-related fitness phenotypes: the 2003 update. Med Sci Sports Exerc 2004; 36: 1451-1469.

37 Plotnikoff RC, Brez S, Hotz SB: Exercise behavior in a community sample with diabetes: understanding determinants of exercise behavioral change. Diabetes Educ 2000; 26: 450-459.

38 Walcott-McQuigg JA: Psychological factors influencing cardiovascular risk reduction behaviour in low and middle income African American women. J Natl Black Nurses' Assoc 2000; 11: $27-35$.

39 McCaleb A: Global and multidimensional self-concept as a predictor of health practices in middle adolescents. $J$ Child Adolesc Psychiatr Nurs 1995; 8: 18-26.

40 Macgregor ID, Regis D, Balding J: Self-concept and dental health behaviours in adolescents. J Clin Periodontol 1997; 24: 335-339.

41 Noakes TD: Tainted glory-doping and athletic performance. N Engl J Med 2004; 351: 847-849.

42 Bjerklie D, Park A: How doctors help the dopers. Time 2004; 164: 58-62.

43 Henn W: Consumerism in prenatal diagnosis: a challenge for ethical guidelines. J Med Ethics 2000; 26: 444-447.

44 Knoppers BM, Isasi RM: Regulatory Approaches to reproductive genetic testing. Hum Reprod 2004; 19: 2695-2701.

45 American Medical Association: Ethical issues related to prenatal genetic testing. The Council on ethical and judicial affairs. Arch Fam Med 1994; 3: 633-642.

46 William C, Alderson P, Farsides B: Too many choices? Hospital and community staff reflect on the future of prenatal screening. Soc Sci Med 2002; 55: 743-753.

47 Murray TH: Assessing genetic technologies. Two ethical issues. Int J Technol Assess Health Care 1994; 10: 573-582. 